in amounts which can supply local markets; others would supply a limited overseas demand; and still others are capable of supplying a large export market." The species treated of in the pamphlet of the so-called 'A Ash Group' are Eucalyptus regnans, gigantea, obliqua, sieberiana, fastigiata, oreades, fraxinoides and consideniana.

\section{British Breed Standards of Domestic Animals}

A BREED standard, well-defined though it may be at the moment, is a fluctuating measure of quality, and Herbert Haseltine has done good work for science as well as for art in creating the sculptures of typical British champions of domestic breeds at the present day. The series of statuettes, nineteen in number, cast in bronze or carved in stones of various hues and textures, chosen to suggest the colours and characteristics of the animals, was exhibited in London and Paris in 1925, and now, thanks to the generosity of Marshall Field, has taken its place as a permanent exhibit in the Field Museum of Natural History in Chicago. A pamphlet (Zoology Leaflet, 13) has just been issued by the Museum, illustrating and describing briefly the models in this unique series, which is a permanent tribute to the skill of the stockbreeders of Great Britain.

\section{Drought and Disease in Lambs}

As a result of the prolonged drought of last year, a bad outbreak of 'stomach-worm disease' or 'scouring' developed in lambs during the late part of autumn and early winter, causing heavy losses to sheep in many parts of Great Britain. There can be little doubt that the outbreak was due to deficiency in food, owing to the shortage of grass, for such a condition has been found to lead to a great increase in the numbers of parasitic worms. To prevent severe infestation it is necessary to keep up the condition of the lambs. The weather conditions of the present year in many ways resemble those of last year, and there is danger of a recurrence of stomach-worm disease with its attendant losses. Farmers and others interested are therefore recommended to apply for the account of the life-history of the parasitic worms, with information about their distribution and control, published as Leaflet 75 by the Ministry of Agriculture and Fisheries and issued free of charge.

\section{Oil in Western Canada}

THE fact that the second edition of "Oil and Gas in Western Canada" by G. S. Hume (Canada, Dept. Mines, Econ. Geol., Ser. 5, 1933) contains twice as many pages as the first is an indication of the mass of new data of oil and gas prospects in western Canada acquired during the last five years. The author has wisely refrained from amplifying to any marked extent the brief introductory chapter on oil origin and accumulation, but the additional illustrations of various types of structures certainly make his digest more palatable both to the uninitiated and to those familiar with the subject. In view of the rapid advancement of geophysical science and its now widespread application, the chapter on this subject is still too brief and sketchy to be of real technical value. In the first edition, a chapter was devoted to a survey of carbon ratios in relation to known occurrences of oil and gas, emphasis being laid on the fact that favourable structures can be determined by means of these ratios ; it is therefore significant that this section has been omitted in the second edition. The additional information given is wholly relevant to the main issue, and serves as a useful basis of comprehension of the actual descriptions of oil and gas fields. Order and proportion are given to these descriptions, and valuable technical data contained therein made more accessible by division of the region under review into seven districts, namely, the Foothills, Southern, Central, and Northern Plains of Alberta, the Plains of Manitoba and Saskatchewan, Northwest Territories, and British Columbia. Lack of an index, however, to such a large volume is a decided disadvantage.

\section{Safety in Mines Research Board}

THE Safety in Mines Research Board has just issued its twelfth annual report; this report is always looked forward to with a good deal of interest by all connected with coal mining in Great Britain, and this twelfth report is especially interesting because it includes a report on matters that come under the purview of the Health Advisory Committee. The subjects dealt with are exceedingly wide, but all have bearing on the safety of men engaged in any way in coal mining. A number of the detailed reports, which are contained in appen. dixes to the main report, have already been published, chiefly in the Transactions of the Institution of Mining Engineers, and these are exceedingly important. It is also of the greatest interest to find that this Board is co-operating with similar bodies in other countries, and especially with the United States Bureau of Mines, with the French, German, Belgian and other interested bodies.

\section{French Mathematical Tracts}

Fon the last six years the well-known Paris publishers Hermann et Cie. have been issuing brief but authoritative accounts of recent research work in many fields under the general title of "Actualités scientifiques et industrielles". Several of the latest additions to this series are of a mathematical nature, and are grouped under various sub-headings such as "Exposés d'Analyse Générale" (which deal with developments of Cantor's theory of aggregates), "Exposés de Géométrie", and "Exposés mathématiques". One of the tracts placed in the third group might very well have been included in the first. The authors include M. Fréchet, Emmy Noether (who writes in German), A. Appert, M. Brelot, J. Dieudonné, L. Godeaux and N. Lusin. Some of these confine themselves to rather special problems investigated by themselves, while others, notably MM. Fréchet and Appert in their "Exposés d'Analyse Générale", give a general account of all the results obtained in the field considered. The number of pages in a tract varies from 11 to 63 , and the price from 5 to 14 francs. The style has the clarity and charm which are characteristic of French exposition. 